\title{
Indoor and Outdoor Play in Preschool Programs
}

\author{
Julia Kroeker \\ School of Education, Florida SouthWestern State College, United States
}

Copyright $(2017$ by authors, all rights reserved. Authors agree that this article remains permanently open access under the terms of the Creative Commons Attribution License 4.0 International License

\begin{abstract}
The purpose of this study was to explain children's indoor and outdoor play in preschool programs in terms of teacher interaction, peer interaction and task orientation. Children's indoor and outdoor play behaviors were compared using the Individualized Classroom Assessment Scoring System (inCLASS). Findings included significant differences on task engagement and self-reliance (within the domain of task orientation), with both measures higher in an indoor play environment than an outdoor environment. Findings revealed no significant differences between the indoor and outdoor environment in terms of teacher engagement and peer engagement.
\end{abstract}

Keywords Play, Preschool, Indoor, Outdoor

\section{Introduction}

\subsection{Statement of the Problem}

The importance of play in early childhood education is well-documented [1-3]. We know little about differences in how children play indoors versus outdoors [1]. In this study, children's play in two settings: indoors and outdoors, is compared. Both settings are essential to children's healthy development [1]. We see differences in specific play behaviors and domains affected relative to the setting [1].

Initiatives increasing the academic focus in preschools have resulted in children spending more time in adult-directed activities as opposed to child-initiated play [4]. In addition, $40 \%$ of American elementary schools have either eliminated or considered eliminating recess in order to have more perceived instructional time [5]. While the importance of play continues to be widely accepted, teacher training relative to effective facilitation of play remains a need. As a result of this shift toward more adult-directed activities, it is particularly important to learn about the influence of setting, especially in early childhood programs. This study compared and contrasted play of preschool age children with their peers, teachers, and environment. This article will concentrate on the quantitative results of a mixed methods study.

\subsection{Research Questions}

RQ1. How does children's play differ between an indoor and outdoor play setting?

Sub-questions include the following:

- Do teacher interactions with individual children differ between an indoor play environment and an outdoor play environment?

- Do children's peer interactions differ between an indoor play environment and an outdoor play environment?

- Does individual children's task orientation differ between an indoor play environment and an outdoor play environment?

RQ2. Do the significant results for task engagement hold up for children of different ages and for both genders, and for the different preschool sites?

\section{Methods and Materials}

\subsection{Data Collection}

\subsubsection{Sites and Materials}

Four different sites in a rural Midwestern state participated in the study. Two of the sites were child care centers on university campuses, and the other two were Head Start programs. The preschool sites were all-day programs, and three of the four sites operated year-round. The indoor environments were organized into learning centers and included areas such as: art, blocks, dramatic play, manipulatives, and library. The indoor environments varied greatly in size, materials available, and organization. The playgrounds and outdoor play areas differed substantially among sites. Three of the four sites were accredited by the National Association for the Education of Young Children (NAEYC).

Some open and closed-ended materials were available to children during the indoor and outdoor play. The materials were provided by the centers. Materials that were available in both settings included: wooden blocks, six scarves, and three blankets, three dolls, six cars/trucks, and a bucket full of small plastic people. Two of the sites had additional 
materials available to children outdoors. These materials included a broom, tricycles and small animals for dramatic play near the sandbox. In addition, some playgrounds had opportunities for large motor play on slides, poles, etc. The indoor environments had many more materials that were not available outdoors, such as manipulatives, art materials, books, and others.

\subsubsection{Participants}

The participants were 30 preschool children at four different sites in a rural Midwestern state. Teachers supplied informed consent and participants were recruited from each classroom with teacher consent. In order to obtain a large enough sample size for the data analysis, all children with informed consent participated in the study. Six children participated from the first site, thirteen children from the second site, nine children from the third site, and two children from the fourth site.

The sample was comprised of $46.7 \%$ males and $53.3 \%$ females, with the children's ages ranging from 38-70 months, with a mean age of 52.14 months. The majority of participants were white $(70 \%)$, while $20 \%$ were Asian, $13.3 \%$ were black, and $3.3 \%$ were American Indian or Alaska Native, and $6.7 \%$ were other/unknown race. A percentage of the sample $(13.3 \%)$ was identified as being of more than one race. Most of the children in the sample spoke English (83.3\%), but many other languages were also spoken in the homes of the participants. In $20 \%$ of the participants' homes, more than one language was spoken. The annual household income for $66.7 \%$ of participants was $\$ 30,000$ or more, while $26.7 \%$ of participants come from a family with an annual income of less than $\$ 30,000$. The education level of the participants' parents varied substantially, with $20 \%$ of mothers and $20 \%$ of fathers having terminal degrees in their field. Demographic information on the participants was obtained from a questionnaire given to the parents of the participants.

\subsubsection{Measure}

The Individualized Classroom Assessment Scoring System (inCLASS) [6] was used to measure individual children's interactions in an indoor and outdoor setting. Three types of interactions, referred to as domains by the authors, included teacher interactions, peer interactions, and task orientation. Teacher interaction measures, termed dimensions by the authors, included positive engagement with the teacher, teacher communication, and teacher conflict. Peer interaction dimensions included peer communication, peer assertiveness and peer conflict. Task orientation dimensions included engagement with tasks, self-reliance, and behavior control. The descriptions of the dimensions, from the inCLASS Coding Manual [6], are listed below in Table 1 .

Table 1. Domains and Dimensions of the inCLASS and Descriptions of the Dimensions

\begin{tabular}{|c|c|c|}
\hline Domains & Dimensions & $\begin{array}{l}\text { Description of What is Being Measured by the Dimension } \\
\text { The degree to which... }\end{array}$ \\
\hline \multirow{3}{*}{$\begin{array}{l}\text { Teacher } \\
\text { Interactions }\end{array}$} & Positive Engagement with Teacher & $\begin{array}{l}\text { The child is emotionally connected to the teacher(s) and adults, including seeking and } \\
\text { enjoying interactions with them, and using them as a secure base. }\end{array}$ \\
\hline & Teacher Communication & $\begin{array}{l}\text { The child initiates and maintains conversation with the teacher(s) and adults while using } \\
\text { language as a functional tool to make needs, emotions, and opinions known. }\end{array}$ \\
\hline & Teacher Conflict & $\begin{array}{l}\text { The child's interactions with the teacher(s) and adults are characterized by tension, } \\
\text { resistance, and negativity. }\end{array}$ \\
\hline \multirow{4}{*}{$\begin{array}{l}\text { Peer } \\
\text { Interactions }\end{array}$} & Peer Sociability & $\begin{array}{l}\text { The child experiences positive emotions and behaviors with other children, including the } \\
\text { tendency to seek peer interactions, show social awareness and respond in a manner that } \\
\text { peers react positively to. }\end{array}$ \\
\hline & Peer Communication & $\begin{array}{l}\text { The child initiates and maintains conversation with other children while using language as } \\
\text { a functional tool to make needs, emotions, and opinions known. }\end{array}$ \\
\hline & Peer Assertiveness & $\begin{array}{l}\text { The child uses positive strategies to initiate and lead interactions with other children and } \\
\text { the degree to which those strategies are successful. }\end{array}$ \\
\hline & Peer Conflict & $\begin{array}{l}\text { The child's interactions with other children are characterized by tension, resistance, and } \\
\text { negativity. }\end{array}$ \\
\hline \multirow{3}{*}{$\begin{array}{l}\text { Task } \\
\text { Orientation }\end{array}$} & Engagement within Tasks & $\begin{array}{l}\text { The child is consistently and actively involved in classroom tasks and activities, including } \\
\text { the amount of time the child remains focused on any given activity, the level of intensity or } \\
\text { enthusiasm displayed, and the proportion of time the child spends on assigned activities. }\end{array}$ \\
\hline & Self-Reliance & $\begin{array}{l}\text { The child takes learning into their own hands, including seeking opportunities rather than } \\
\text { passively waiting for teacher direction, and making the best use of classroom resources. }\end{array}$ \\
\hline & Behavior Control & $\begin{array}{l}\text { The child regulates movement, physical activity, and verbalizations, so that these match the } \\
\text { expectations of the setting. }\end{array}$ \\
\hline
\end{tabular}


This is an observational instrument, so the researcher did not need to interact with the children, but simply observed and scored each individual child on the assessment. The trained researcher observed four children per hour for two observational cycles (one observation indoors and one observation outdoors), using a 15-minute rotation (observation for 10 minutes, followed by coding for 5 minutes). The data collection was completed from May through July of 2014.

\subsection{Data Analysis}

To analyze the data and answer the research question, 10 separate within-group Analysis of Variance (ANOVA) tests were run to analyze inCLASS score differences between an indoor and outdoor play environment. An ANOVA was run for each of the inCLASS dimensions within the three domains: positive engagement with the teacher, teacher communication, and teacher conflict (teacher interactions); peer sociability, communication, peer assertiveness, and peer conflict (peer interactions); and engagement within tasks, self-reliance, and behavior control (task orientation). Dimension scores were used because (1) reliability scores had been obtained at the dimension level, (2) dimensions were believed to provide more detail in comparing indoor and outdoor play, and (3) there is more variability in how the authors have factored domains with this relatively new measure [6], although there was consideration of greater chance of type 1 error using 10 dimensions versus three domain analyses. The significant results were then examined to see if age and preschool site were relevant factors.

\section{Results}

Before investigating the specific sub-questions, the descriptive characteristics of the data were investigated to determine if variables demonstrated ceiling or floor effects or lacked variability. The descriptive data are reported in Table 2 below.

While the in CLASS had a range of scores of 0-7, there were only four dimensions that had the full range of scores in both environments: positive engagement with the teacher, teacher communication, peer communication, and peer assertiveness. There were two sub-scales that had a range of 1-7 in both environments: peer sociability and self-reliance. There were four dimensions that had a much more limited range of scores: teacher conflict ( $0-2$ inside and $0-1$ outside), peer conflict ( $0-4$ in both environments), engagement in tasks (3-7 inside and 2-7 outside), and behavior control (4-7 in both environments).

The dimensions with the lowest means were teacher conflict with a mean of 0.2 inside and 0.07 outside and peer conflict with a mean of 0.67 indoors and 0.57 outdoors. The dimensions with the highest means were engagement in tasks (6.2 indoors and 5.2 outdoors) and behavior control (6.17 indoors and 6.0 outdoors).

Most of the time, children did not have high scores in all of the three domains (teacher engagement, peer engagement, task orientations), but were more likely to have high scores in one or two of the domains. The correlation coefficients among the domains indoors are shown below in table 3 . The peer interactions domain was negatively correlated with teacher interactions during indoor play. This provides some evidence that children were not likely to score high on all three domains of the in CLASS.

Table 2. Dimensions of inCLASS with the Range, Mean and SD for Each, Indoors and Outdoors

\begin{tabular}{|c|c|c|c|c|}
\hline Scale & Range Indoors & Range Outdoors & Mean Indoors & Mean Outdoors \\
\hline \multicolumn{5}{|c|}{ Teacher Interactions } \\
\hline Positive Engagement & $0-7$ & $0-7$ & $2.83(2.49)$ & $2.56(2.33)$ \\
\hline Teacher Communication & $0-7$ & $0-7$ & $2.43(2.31)$ & $2.03(2.22)$ \\
\hline Teacher Conflict & $0-2$ & $0-1$ & $.20(.48)$ & $.067(.25)$ \\
\hline \multicolumn{5}{|c|}{ Peer Interactions } \\
\hline Peer Sociability & $1-7$ & $1-7$ & $4.6(2.17)$ & $4.76(2.11)$ \\
\hline Peer Communication & $0-7$ & $0-7$ & $3.87(2.51)$ & $3.80(2.35)$ \\
\hline Peer Assertiveness & $0-7$ & $0-7$ & $3.80(2.25)$ & $3.87(2.01)$ \\
\hline Peer Conflict & $0-4$ & $0-4$ & $.67(1.03)$ & $.57(.94)$ \\
\hline \multicolumn{7}{|c|}{ Task Orientation } \\
\hline Engagement in Tasks & $3-7$ & $2-7$ & $6.20(1.09)$ & $5.20(1.32)$ \\
\hline Self-Reliance & $1-7$ & $1-7$ & $4.60(1.38)$ & $3.90(1.45)$ \\
\hline Behavior Control & $4-7$ & $4-7$ & $6.17(1.05)$ & $6.00(.87)$ \\
\hline
\end{tabular}


Table 3. Correlations among Teacher Interactions, Peer Interactions, and Task Orientation During Indoor Play

\begin{tabular}{|c|c|c|c|}
\hline Domains & Teacher & Peer & Task \\
\hline Teacher & 1.00 & -0.25 & 0.03 \\
\hline Peer & -0.25 & 1.00 & 0.51 \\
\hline Task & 0.03 & 0.51 & 1.00 \\
\hline
\end{tabular}

A similar trend occurred outdoors, where it was rare for a child to score high in all three domains. Table 4 shows the correlation coefficients outdoors for the three inCLASS domains. Again, the teacher interactions domain was negatively correlated with peer interactions. Outdoors, teacher interactions were also negatively correlated with task orientations, and children were not likely to score high in all three domains. Outdoors, there are high correlations between peer interactions and task orientations; if one of these domains had a high score, the other likely did as well.

Table 4. Correlations among Teacher Interactions, Peer Interactions, and Task Orientation During Outdoor Play

\begin{tabular}{|c|c|c|c|}
\hline Domains & Teacher & Peer & Task \\
\hline Teacher & 1.00 & -0.56 & -0.28 \\
\hline Peer & -0.56 & 1.00 & 0.76 \\
\hline Task & -0.28 & 0.76 & 1.00 \\
\hline
\end{tabular}

\subsection{Research Question 1}

How does children's play differ between an indoor and outdoor play setting?

\subsubsection{Sub-question 1}

Do teacher interactions with individual children differ between an indoor play environment and an outdoor play environment? To answer the first sub-question of the quantitative research question, three separate within-group ANOVAs were run to examine differences between the indoor and outdoor play of the preschool children in terms of their interactions with the teachers. The three ANOVAs compared the three different dimensions of child-teacher interactions between the indoor and outdoor play environment as evidenced by inCLASS data. All three of the ANOVAs showed no significant differences between the indoor and outdoor environments.

It had been hypothesized that children would interact with teachers less outdoors, and that there would be less teacher conflict. In this study, however, teachers engaged with children outdoors as much as they did indoors.

\subsubsection{Sub-question 2}

Do children's peer interactions differ between an indoor play environment and an outdoor play environment?

The second sub-question of the quantitative research question was answered using the same procedures as for the first sub-question. However, this time, four separate within-group ANOVAs were run to compare the four different dimensions of peer interactions: peer sociability, peer communication, peer assertiveness, and peer conflict. Again, all of these ANOVAs revealed no significant differences between the indoor and outdoor environments in terms of peer interactions.

\subsubsection{Sub-question 3}

Does individual children's task orientation differ between an indoor play environment and an outdoor play environment? To answer the third sub-question of the quantitative research question, three separate within-group ANOVAs were run to examine the differences between the indoor and outdoor environment for three dimensions of task orientation: engagement within tasks, self-reliance, and behavior control. While there were no significant differences between the two play environments for behavior control, significant differences were found for engagement within tasks $F(1,29)=11.15, p<.01$, as shown in Table 5 below. The difference for self-reliance was also significant $F(1,29)=5.18, p<.05$. Task engagement and self-reliance were found to be higher indoors than outdoors. This is the opposite of the hypothesized results; as it was hypothesized that both of these dimensions would be higher outdoors.

Table 5. F Values and Significance of ANOVAs for the inCLASS Dimensions

\begin{tabular}{|c|c|c|c|c|}
\hline Dimension from inCLASS & Domain, Sub-question & df & F Value & $\mathrm{p}$ \\
\hline Positive Engagement with Teacher & Teacher, 1 & 1 & .32 & .58 \\
\hline Teacher Communication & Teacher, 1 & 1 & 1.05 & .32 \\
\hline Teacher Conflict & Teacher, 1 & 1 & 1.05 & .32 \\
\hline Peer Sociability & Peers, 2 & 1 & 1.05 & .32 \\
\hline Peer Communication & Peers, 2 & 1 & .02 & .89 \\
\hline Peer Assertiveness & Peers, 2 & 1 & .03 & .87 \\
\hline Peer Conflict & Peers, 2 & 1 & .15 & .70 \\
\hline Engagement within Tasks & Task, 3 & 1 & 11.15 & .00 \\
\hline Self-Reliance & Task, 3 & 1 & 5.18 & .03 \\
\hline Behavior Control & Task, 3 & 1 & .71 & .41 \\
\hline
\end{tabular}


While using ten separate ANOVAs raised the risk of a type 1 error, more details were discovered by examining each of the ten dimensions. Additionally, when only three ANOVAs were run for the domains, there was still a significant difference found for the domain of task orientation (differences were found for the dimensions of task engagement and self-reliance).

\subsection{Research Question 2}

Do the significant results for task engagement hold up for children of different ages and for both genders, and for the different preschool sites?

Because there was a wide range in ages, it would not be surprising to find differences on scores based on the child's age. ANOVAs were completed to test for moderation effects by adding age and gender and age $\mathrm{x}$ environment and gender $\mathrm{x}$ environment interactions to indoor vs. outdoor scores for task engagement and self-reliance. There was a main effect for age, with scores for task engagement $F(1,55)=6.49$, $p=0.01$, and self-reliance, $F(1,55)=19.55, p=0.00$, going up with the children's age, as expected. However, when the researcher tested for moderation effects, there was no interaction between age and environment (indoor and outdoor) for self-reliance, $F(1,55)=0.5, p=0.48$, or task engagement, $F(1,55)=0.85, p=0.36$. There was also no main effect for gender and no interaction for gender and environment for self-reliance, $F(1,55)=1.01, p=0.32$, or for task engagement, $F(1,55)=0.44, p=0.50$.

\section{Discussion}

This study examined children's indoor and outdoor play in terms of teacher interaction, peer interaction, and task orientations using the inCLASS. It was discovered that there were significant differences between the indoor and outdoor environments for some dimensions. The dimensions where differences were found were self-reliance and task engagement. These two dimensions were found to be higher indoors than outdoors, which is the opposite of what was hypothesized. It is important to consider why children scored higher on self-reliance and engagement indoors than outdoors when interpreting these somewhat surprising findings.

First, it is helpful to understand what is happening--and not happening-- when a child is observed to be highly self-reliant and engaged. As stated previously, children typically did not score high in all three domains. Many times, children scored higher in one or two domains, and lower in one. Sometimes, children were more highly engaged in teacher and/or peer interactions, and not as engaged in the task at hand. Other times, children were more highly engaged in the task, but not engaged in peer and/or teacher interaction. To the researcher's knowledge, former inCLASS studies including the inCLASS Pilot Study and inCLASS Field
Study, have not presented correlations of the domains [6].

Movement play is a lower level of cognitive play [7] than dramatic and constructive play, and this may explain why children were more engaged indoors; higher-levels of cognitive play tend to require more intensive engagement.

There are additional reasons why children could have been more engaged indoors. Several of the outdoor environments were very large, with numerous types of materials and activities available to children, beyond those that were comparable between the indoor and outdoor environments. Although some materials were brought outside during the data collection and some sites had materials available at all times, there were activities and materials that were available outside that are not available inside. Children may have chosen to meet under a tall tree and slide and climb because these activities were only available outdoors. This may have led to children being engaged in movement play outdoors much of the time. Also, because the play areas were so large in many cases, it may have made it more difficult for children to focus on one task.

Children's self-reliance was found to be significantly higher indoors than outdoors during free play as well. However, this finding was not as predictable as the results for task engagement. There were 7 children out of 30 in the sample who scored lower on self-reliance indoors when compared to self-reliance outdoors, and five children had no difference in self-reliance between the two environments. The significant difference was probably found because when children did score higher on self-reliance indoors, it was usually much higher. It could be that because children were more engaged in higher levels of cognitive play indoors, they needed to be more self-reliant in the tasks because the tasks were more difficult. For example, it does not take a lot of self-reliance for preschoolers to go down a slide when playing outdoors, but most of the time, they do this without assistance. In addition, a child may not always be able to get the attention and/or assistance of the teacher in a large preschool class.

It should be noted that the teacher has many roles during children's play and the degree to which the teacher tries to direct the child's play may affect the child's self-reliance. While the teacher is often engaged in play with children, it is imperative that the teacher not take over the child's play, but let children direct their own play. If the activity is teacher-directed, then it can be argued that it is not truly play, but the child adhering to the adult's agenda.

Behavior control was the only dimension of task orientations that was not found to differ significantly between the two play environments. The variability of behavior control was not as high as that of task engagement and self-reliance in either environment. According to the inCLASS Pre-K Coding Manual, there is good variability for most of the inCLASS dimensions in previous studies, but the dimension of behavior control was positively skewed in previous studies [6].

It was hypothesized that teacher engagement with children 
would be different outdoors from what it is indoors, and that there would be more teacher interaction outdoors and less teacher conflict. Although in past studies, it had been found that adult-child interaction was more frequent indoors than outdoors [8], the programs where the data were collected in the current study were high-quality programs (all but one site were NAEYC accredited). Possibly these programs have teachers who understand the importance of the teacher interactions regardless of the play setting. For two dimensions of teacher engagement, positive engagement with the teacher and teacher communication, there was much variation. However, for teacher conflict, there was not as much variation. Had there been more variation in scores of teacher conflict, it is possible that there would have been a greater likelihood of finding a significant difference.

It was also hypothesized that peer interactions would occur more frequently outdoors and that there would be less peer conflict. While lowered stress and anger have been known to occur simply by viewing nature and natural scenes [9], these children's stress levels may have been lowered simply by engaging in free play inside the classroom as well. In addition, the classrooms had windows where children could view nature even while engaged in free play indoors. The peer interaction domain has four dimensions: peer sociability, peer communication, peer assertiveness and peer conflict. Two of the dimensions, peer communication and peer assertiveness, had high variability inside and outside, with means for the two environments very similar to each other. Peer sociability also had much variability in both environments. Peer conflict had much less variability. Again, this lower variance made it less likely that a significant difference would be found. The data also demonstrate that there was not a substantial difference in children's peer interactions indoors and outdoors, and the variability was similar in both environments.

\subsection{Significance of the Study}

The present study is significant because there has been limited research on preschool children's indoor and outdoor play. In fact, there is very little literature with which to compare current results. There was only one other study found that compared indoor and outdoor play, and it occurred in a Japanese preschool [1]. The Japanese preschool study compared only indoor and outdoor play. The current study demonstrates that in some preschool programs, children are more engaged and self-reliant in tasks during free play indoors than outdoors. Thus, the current study makes a number of specific contributions.

First, the study contributes by the way indoor play and outdoor play is examined. Many studies that provide measurement within early childhood programs focus on the program that occurs indoors [10-11]. The current study offers a different paradigm that suggests the program occurs both indoors and outdoors. The play and work in these two settings may be the same or different and complementary but the assumption is that both settings matter in ways that can be measured. Such a view is likely to be of growing interest giving increasing importance ascribed to natural and outdoor environments. So, the first contribution is that it is assumed that the program encompasses both indoor and outdoor environments.

Similarly, the study contributes by bringing early childhood education measures to the outdoor setting-measures that are commensurate to what is used in indoor settings. While the inCLASS, which is a relatively new measure, has been used in indoor settings and has followed the child into outdoor settings, its use to describe play in both settings is new. Thus, some may consider the use of the inCLASS in comparing indoor and outdoor settings to be an innovative use of the inCLASS. This is valuable information, as research has shown that the inCLASS domains are tied to success in school [6]. As pointed out in the inCLASS manual [6], there are not a lot of psychometrically sound measures that examine these classroom interactions (domains).

Next, the study contributes in the nature of its quantitative findings suggesting that children's engagement and self-reliance may be quite different in the two settings. The study does seem to suggest that children may require the materials and features of the classroom routine for deep concentration, but it opens the door to explore what it would take to create conditions for deep and sustained engagement in outdoor preschool settings, and what deep and sustained engagement means in outdoor settings when other forms of important play, such as movement-oriented play, may be taking place.

\subsection{Implications of Conclusions}

Children were more engaged in tasks during indoor free play than during outdoor free play. This may be true in part because many children were engaged in movement play outdoors and had more room; therefore, children were more likely to change activities and move around more than during indoor play.

While the scores for task engagement were higher for indoor play, there are many benefits of children's outdoor play as well. Children, when outdoors, participated in movement play much of the time. While participating in movement play, children had the opportunity to practice large and small motor skills. It has also been shown that physical exercise improves brain functioning and cognitive processes [12]. Because of these benefits of outdoor play, as well as the benefits afforded children during indoor play, preschool programs should give children ample time and opportunity to engage in child-initiated free play in both environments every day. Play indoors and outdoors seemed to be complementary in this study. While, for the most part, the relationships hypothesized in this study were not substantiated, there is still a great deal to be learned about how indoor and outdoor play complement and contribute to 
children's developing competencies.

\section{REFERENCES}

[1] T. Hirose, N. Koda, T. Minami. Correspondence Between Children's Indoor and Outdoor Play in Japanese Preschool Life, Early Childhood Development and Care, Vol. 182, 1611-1622.

[2] L. Maxwell, M. Mitchell, G. Evans. Effects of Play Equipment and Loose Parts on Preschool Children's Outdoor Play Behavior: An Observational Study and Design Intervention, Children, Youth, and Environments, Vol. 18, No. 2, 36-63.

[3] V. McLoyd. The Effects of the Structure of Play Objects on the Pretend Play of Low-Income Preschool Children, Child Development, Vol. 54, 626-635.

[4] C. Copple, S. Bredekamp. Developmentally Appropriate Practice in Early Childhood Programs Serving Children from Birth through Age 8, National Association of the Education of Young Children, Washington, DC, 2009.

[5] R. Louv. Last Child in the Woods: Saving our Children from Nature-Deficit Disorder, Algonquin Books of Chapel Hill, Chapel Hill, NC, 2008.
[6] J. Downer, L. Booren, B. Hamre, R. Pianta, A. Williford. inCLASS Observation: The Individualized Classroom Assessment Scoring System Pre-K Coding Manual, Center for Advanced Study of Teaching and Learning (CASTL), Charlottesville, VA, 2012.

[7] K. Rubin. Play Behaviors of Young Children, Young Children, Vol. 32, No. 6, 16-24.

[8] L. Harper, K. Huie. Free Play Use of Space by Preschoolers From Diverse Backgrounds: Factors Influencing Activity Choices, Merrill-Palmer Quarterly, Vol. 44, No. 3, 423-446.

[9] B. Kweon, R. Ulrich, V. Walker, L. Tassinary. Anger and Stress: The Role of Landscape Posters in an Office Setting, Environment and Behavior, Vol. 40, 355-381.

[10] E. Reynolds, K. Stagnitti, E. Kidd. Play, Language and Social Skills of Children Attending a Play-Based Curriculum School and a Traditionally Structured Classroom Curriculum School in Low Socioeconomic Areas, Australasian Journal of Early Childhood, Vol. 36, No. 4, 120-130.

[11] S. Neuman, K. Roskos. Access to Print for Children of Poverty: Differential Effects of Adult Mediation and Literacy-Enriched Play Settings on Environmental and Functional Print Tasks, American Educational Research Journal, Vol. 30, 95-122.

[12] P. Tomporowski, C. Davis, P. Miller, J. Naglieri. Exercise and Children's Intelligence, Cognition, and Academic Achievement, Educational Psychology Review, Vol. 20, No. $2,111-131$ 